\title{
Distance education influence on medical students readiness for educational and professional self-development
}

\author{
Nataliya Gromakova*, and Irina Plotnikova \\ Voronezh State Medical University named after N.N. Burdenko, Studencheskaya street, 10, 394036 \\ Voronezh, Russia
}

\begin{abstract}
The article presents an analysis of domestic and foreign specialists attitudes regarding modern trends in the development of distance education and the forced transition of all educational organizations to online learning in connection with the COVID-19 pandemic. The article reflects the results of an empirical research aimed at studying the readiness of medical students for educational and professional self-development in the context of distance education.
\end{abstract}

\section{Introduction}

Distance education, despite the ambiguous attitude of world educational community representatives towards it, is becoming an increasingly common form of the educational process organization. Distance education began in the late 18th century in Great Britain. Isaac Pitman, a stenography instructor, passed on teaching material to students and assessed learning outcomes by mail. The main idea was to provide an opportunity to get higher education for everyone, regardless of origin, nationality, wealth. At the end of the 19th century, a distance education faculty was opened at the University of Chicago, and in 1969 the world's first open university was established in Great Britain, the main mission of which was to provide affordable education for all segments of the population. Open universities were also created in our country - by the $1960 \mathrm{~s}$, there were 11 universities of this type in the USSR. In 1979, radio university programs and television education courses were launched in China.

Distance education was carried out mainly in the format of correspondence education, involving orientation sessions, in which students received basic information, assignments and materials for independent study. Twice a year, students came to the educational organization to receive tune-up information and pass intermediate control.

The distance education possibilities and scope of implementation have expanded significantly with the advent of Internet technologies. So, in 2015 , the majority of specialists in the field of higher education (doctors and candidates of sciences, holding managerial positions in educational organizations), included in the process of introducing and implementing online learning in the educational process and acted as experts in the study by

\footnotetext{
* Corresponding author: nat-vp@yandex.ru
} 
A. A. Sevastyanova [1], noted the extreme importance of distance education, the high level of its actual and potential demand for the Russian educational system. At the same time, about half of 90 experts indicated that teachers were wary about the prospects of teaching "distance students" [1]. A. A. Sevastyanova believes that the reason for this is the technical unpreparedness of many educational organizations for the implementation of online learning, the absence of specially trained personnel for its realization. In our opinion, this is far from the only reason for the teachers' wariness. Doubts about its quality play a significant role in such an attitude towards distance education; the impossibility of direct interaction between the teacher and the student, which gives rise to a lack of a social component in the educational process; lack of competition between students, which is a significant factor of involvement in educational and professional activities; a significant decrease in the foster component of educational activity and a number of other reasons.

A research conducted by N.P. Narbut, I. A. Aleshkovsky and others [2] in 2020, which covered 3431 teachers of Russian universities, revealed a number of problems that significantly reduce the effectiveness of distance learning organization. First of all, these are the difficulties of motivating and implicate students in the educational process; lack of developed technologies to organize group work of students and adequate forms of their knowledge control; professional and personal unwillingness of teachers to carry out online learning.

Despite multiple doubts both among educational specialists and among employers of graduates (legitimacy and quality of education), distance education is becoming a system of the educational process throughout the world.

A. Zayum and O. Zawatski-Richter [3] analyzed the state of open and distance education in 12 countries, including Russia, whose population is more than half of the world's population. Accordingly, the results and conclusions obtained reflect the picture of most of the modern educational space.

Open education involves self-directed learning using educational media. Distance education also includes online or e-learning (using information and computer technologies), blended (hybrid) and flexible learning. Distance education is seen as an alternative to correspondence education. Online learning, as one of the methods of implementing distance education, involves not independent study of the provided content by the student at a convenient time, but in the course of direct contact between the student and the teacher using Internet technologies.

As noted by A. Zayum, O. Zawacki-Richter, in most countries (especially in those where the market economy is actively developing), with the exception of Great Britain and Russia, a significant increase in the number of students in the format of open and distance education has been noticeable in the last 15-20 years. This is due to the growing demand for higher education. As for Russia, authors associate the decline in demand for open and distance education with the continuing decline in the population. In Great Britain, the reason for this trend is seen in the increase in the cost of education, the decrease in the number of adult students in connection with the economic crisis that affected all countries and people living in them of different professions and spheres of activity.

Despite the decrease in the number of students in open and distance courses in Russia, our country surpasses other countries in the ratio of full-time and distance students. If in Russia almost half of the students $(47.0 \%)$ are trained remotely, then, for example, in Germany this share is only 5.5\%; in Britain - 7.7\%; in the USA - 28.4\% [3]. We are talking not only about higher education, but also about advanced training courses, professional retraining and other additional programs. This, in our opinion, explains such a significant proportion of distance learners in our country.

Dominique Orr and his colleagues note that modern higher education is using digitalization to improve the quality of teaching and support students. To this end, education 
focuses on the aspects of flexibility of delivery (in terms of time, place and pace) and openness of delivery (in terms of who has access to learning and who participates in the development of learning content), as both can most significantly benefit from the integration of digital solutions [4].

D. Orr, M. Weller, R. Farrow [4, 5] identified three main aspects of the implementation of online, open and flexible higher education: provision of learning opportunities, content development and formal recognition of learning outcomes. After conducting a global study that covered 150 educational institutions from 36 countries, authors came to the conclusion that the majority of higher education institutions around the world are currently in the process of experimenting with digitalization and the use of new technologies. The introduction of technologies is largely due to the features of the educational organization and has certain nuances depending on the goals of education and meeting the needs of various categories of students. It is advisable to deploy new technologies in the context of pedagogical, business and support models to meet the specific needs of the educational organization and students.

Distance education is considered as a full-fledged part of higher education, providing flexibility and mobility of students, and is actively used in more than $80 \%$ of educational organizations in Europe, Asia, and the United States of America [3]. However, in some countries (for example, India, Turkey), both education specialists and potential employers do not recognize the equivalence and identity of traditional, "live" education and distance education.

changed teachers' methods from the traditional approach, which often places them as educators in

a more flexible approach, where they act more as facilitators, mentors and motivators to inspire students

to participate and learn

changed teachers' methods from the traditional approach, which often places them as educators in

a more flexible approach, where they act more as facilitators, mentors and motivators to inspire students

to participate and learn

In recent decades, namely with the advent of new digital technologies and the global introduction of the Internet, online learning, characterized by cost-effectiveness, adaptability and efficiency, has become the leading method of organizing distance education [6]. As noted by domestic and foreign experts [6;7;8 and others], the outbreak of COVID-19 significantly affected the educational and telecommunications sectors, provoking an increase in demand for online courses and services for their development and implementation (MOODLE, eDX, iSpring, Tutorium, Webinar, ClickMeeting, GoogleClassroom, Udemy, ZOOM, MS Teams, etc.).

As for the productivity of work in a distance format, the teachers of Russian educational organizations who took part in the global research of N.P. Narbut, I. A. Aleshkovsky and others, assessed it as follows: $51.0 \%$ indicated that education is being implemented in full, however, its quality is reduced; $31.3 \%$ noted the preservation of the education quality; $17.7 \%$ assessed distance education as formal, since it is essentially not implemented. "Assessing their experience of work in the distance, more than a third of the respondents noted that the efficiency of work with students has decreased (38.8\%), a quarter (26.1\%) believe that it has decreased slightly, $17.6 \%$ have not noticed any changes, and only $8.4 \%$ believe that their work has become more effective" [2, p. 615]. Almost all teachers $(92.7 \%)$ indicated that, along with a decrease in the efficiency of work with students, their own labor costs increased significantly [2].

N. Mheidly, M. Y. Fares, J. Fares [6] note that the forced transition to distance education using online technologies has changed the traditional approach to teaching, making it more 
flexible; pedagogues acted more as facilitators, motivating and inspiring students. According to the authors, the use of online technologies in teaching helps to increase the efficiency of interaction between teachers and students, and to obtain feedback. In addition, students' interest in educational activities, self-confidence, creativity, as well as, in general, competence and readiness for future professional activities increase. At the same time, the destructive consequences of the pandemic for education are highlighted, which is explained by the imperfection of the technical support of distance education (inaccessibility and interruptions in the Internet, lack of equipment, lack of necessary equipment among lowincome students, etc.).

changed teachers' methods from the traditional approach, which often places them as educators in

a more flexible approach, where they act more as facilitators, mentors and motivators to inspire students

to participate and learn

changed teachers' methods from the traditional approach, which often places them as educators in

a more flexible approach, where they act more as facilitators, mentors and motivators to inspire students

to participate and learn

In our opinion, the disadvantages of distance education are caused not only by the problems of low-income students and poor technical equipment of remote regions residents, but also by a number of other, more significant features of this form of educational activity.

As noted by S.E. Rukshin - people's teacher of Russia, professor of the State Pedagogical University named after V. I. A. Herzen, member of the Public Council under the Ministry of Education, - distance education should not be an independent, but an additional form of education. It is only effective for highly motivated people. In addition, online learning divides, does not allow implementation of the foster component of education. Fostering is not transmitted remotely, "it is transmitted only from person to person. The scientist is brought up by a scientist like the mathematician François Viete, who could not eat for three days, unable to tear himself away from the problem. A surgeon is brought up by a surgeon during operations when a student smells blood" [9].

We agree with the position of S.E. Rukshin, believing that it is advisable to use online technologies in part, as an addition to the forms and methods of traditional education, which makes it possible to directly interact with the subjects of the educational process, to exchange ideas and emotions, without which full-fledged cooperation of trainer and learner is impossible.

However, despite criticism from leading scientists in the higher education system, the trend towards expanding the scope of distance education is obvious. In accordance with this, the need for a deep and comprehensive study of distance education, its impact on the personal and professional development of students, as well as the development of methodologically and theoretically grounded ways and means of improving the quality of this form of education is actualized.

First of all, it is necessary to differentiate the basic concepts - "distance education", "distance learning", "distance educational technologies". Often these definitions are used synonymously, however, distance education includes not only training, but also fostering, which makes it a broader phenomenon. In addition, the researchers emphasize the different levels of these concepts, pointing out that distance education is education implemented using computer and telecommunication technologies, while distance learning involves the interaction of a teacher and students at a distance, while maintaining the components inherent in the educational process, implemented through Internet technologies. or other telecommunication technologies [7, 10, etc.]. Distance education technologies include 
methods and techniques used in the implementation of distance learning. Thus, "distance education is realized through distance learning, in the process of which distance educational technologies are used" [10, p. 6], involving the use of computer technology, software products, Internet resources, etc.

The implementation of distance educational technologies is possible online and offline. The first option involves the interaction of a teacher and students through Internet technologies in a synchronous mode (discussions, conversations, lectures, performing tasks online, interchange of text and other documents). Offline mode is asynchronous and consists in mastering the proposed content (video lectures, tasks for independent work and recommendations for their implementation, test tasks for checking knowledge, etc.) at a convenient time for students.

Obviously, the effectiveness of distance education depends not only on how fully and meaningfully the educational content is presented, not only on the nature of the tasks that students need to complete (reproductive or creative), but also on other components of the educational process, determined by the teacher and the capabilities of the technical means used, but also from the students themselves, their motivation, involvement in educational activities, self-control, discipline, readiness and ability for self-development in educational and professional activities.

In connection with the COVID-19 pandemic in March-June 2019-2020 academic year and in October-January 2020-2021 academic year, the educational process at Voronezh State Medical University (VSMU) named after N.N. Burdenko, as in other educational organizations of our country, was carried out in a distance format. Based on the experience of teaching the discipline "Jurisprudence" at the medical, pharmaceutical and pediatric faculties, we will consider the problem of the readiness of medical students for selfeducation.

To organize the educational process, VSMU teachers used various models of distance learning: consultative, "case technologies", correspondence, regulated self-learning, radio and television, network learning (according to O.M. Goreva) [11]. At the same time, platforms MOODLE and Webinar were used for conducting webinars, online training, conferences.

The implementation of the "case technology" model presupposed the solution of professionally oriented situational tasks by students. To complete these tasks, it was necessary to familiarize yourself with the textbooks, tutorials, text, audio and video materials recommended by the teacher. The effectiveness of this model is due to the actualization of students' search activity, the need to analyze and generalize theoretical information, extrapolate it to the practical situations proposed in the case. A prerequisite for the productivity of this model is the individualization of tasks in order to prevent copying of ready-made solutions. Ideally, the number of situational tasks should correspond to the number of students, which is quite labor-intensive for the teacher who composes them.

The correspondence model included the exchange between the teacher and the students of educational materials, assignments and the results of their implementation. The assignments were of a reproductive and creative nature, were posted by the teacher on the MOODLE platform, as were the necessary teaching materials. Here, the trainers presented the completed tasks for verification.

The model of regulated self-learning, which implies more independence and less regulation of the interaction process, was implemented as follows: after studying the educational material presented on the MOODLE platform (lectures in text and video formats, textbooks, tutorials), students completed tasks for independent work. The results were posted also here. After checking, the teacher gave detailed feedback - in writing or in the format of video conference, which allowed students to understand the strengths and weaknesses of their work, the mistakes made, and to adjust the direction of activity in mastering the educational 
material. The use of this model, in our opinion, is advisable for mastering only a small part of the educational material, since the prevailing reproductive type of educational activity in this case reduces the effectiveness of training future health professionals.

The implementation of the network learning model was also carried out on the basis of the MOODLE platform. Students who have authorized access to the electronic system of the educational organization got acquainted with the educational information posted there and performed the proposed tasks for independent work. The results were presented in a personal account in the MOODLE system. Some of the tasks involved the execution of tests and were automatically assessed by the system. In contrast to the model of regulated self-learning, in this case, the order of mastering the educational material, the process of exchanging information and receiving feedback were more clearly regulated. The final control was carried out using video conference.

Based on the use of telecommunication means of broadcasting information, the radio and television training model was used to conduct orientation lessons, lectures, consultations on seminar-type lessons, and final control. This model maximizes the interactive nature of learning, allowing the teacher and students to interact online. However, there is no possibility of interaction in the "student - student" system, which does not allow organizing the work of students in microgroups or collective discussion of educational material, problematic issues. When teaching students VSMU named after N.N. Burdenko, videoconference was used mainly for lectures and final control by teachers of the departments where the authors work (forensic medicine and jurisprudence; pedagogy and psychology).

The advisory model - a regular visit by students to an advisory center, where they can listen to lectures, meet with teachers, and receive recommendations from them on how to perform independent work - in the context of the COVID-19 pandemic, was not realized by teachers of VSMU named after N.N. Burdenko.

\section{Materials and methods}

To study changes in the level of students' readiness for educational and professional selfdevelopment in the context of traditional and distance learning, a study was conducted in which students of the II-III courses of medical (86 persons), pharmaceutical (16 persons) and pediatric (69 persons) faculties took part. The total sample consisted of 171 people. For the purpose of the study, the methodology "Diagnostics of the level of partial readiness for professional-pedagogical self-development" was modified and standardized for the studied sample (according to N.P. Fetiskin, V. V. Kozlov, G. M. Manuilov) [12, P. 421-424]. Certain statements contained in the questionnaire have been adjusted in accordance with the nature of the educational and professional activities of students - future medical workers, as well as taking into account the emphasis in our study on the formation of the legal competence of medical students.

Students, through self-report, assessed motivational, cognitive, moral-volitional, gnostic, organizational readiness for educational and professional self-development, the ability to self-government in educational and professional activities and communication skills before the start of distance learning and at the present time. To do this, they were asked to doubleassess the severity of the statements presented in the questionnaire. At the first presentation, the instructions indicated that it was necessary to assess their manifestations retrospectively - at the beginning of the second semester of the previous academic year (the instructions did not emphasize that this was the period before the start of distance learning). The second presentation contained the instructions below. The surveys were conducted with an interval of 2-3 days in order to minimize the addictive effect and non-critical repetition of the answers that were given during the first stage of the study. 


\section{Results and discussion}

The results of studying the readiness of medical students for educational and professional self-development, obtained by carrying out two measurements, are presented in Table 1. The column "before" contains the data of the first measurement (before the start of distance learning); in the "after" column - data obtained after the completion of eight months of distance learning.

Table 1. Differentiated groups of medical students by the level of readiness for educational and professional self-development (in\%)

\begin{tabular}{|l|c|c|c|c|c|c|}
\hline \multirow{2}{*}{$\begin{array}{c}\text { Professional self-development } \\
\text { components (SDC) }\end{array}$} & \multicolumn{5}{c|}{ SDC Levels } \\
\cline { 2 - 7 } & \multicolumn{2}{|c|}{ High } & \multicolumn{2}{c|}{ Medium } & \multicolumn{2}{c|}{ Low } \\
\cline { 2 - 7 } & before & after & before & after & before & after \\
\hline 1. Motivational & 32.1 & 21.7 & 50.3 & 52.7 & 17.6 & 25.6 \\
\hline 2. Cognitive & 25.7 & 32.2 & 52.7 & 47.3 & 21.6 & 20.5 \\
\hline 3. Moral-volitional & 14.0 & 22.8 & 67.3 & 55.0 & 18.7 & 22.2 \\
\hline 4. Gnostic & 33.9 & 32.7 & 35.7 & 44.1 & 30.4 & 32.2 \\
\hline 5. Organizational & 19.9 & 25.7 & 45.6 & 35.7 & 34.5 & 38.6 \\
\hline 6. Ability for self-government & 22.8 & 21.6 & 48.5 & 41.0 & 28.7 & 37.4 \\
\hline 7. Communicative & 41.0 & 23.4 & 36.3 & 42.1 & 22.7 & 34.5 \\
\hline
\end{tabular}

As the results of the study have shown, students of a medical educational organization assess their own readiness for educational and professional self-development in different ways before and after the implementation of distance learning. Moreover, for its individual components of educational and professional self-development, both positive and negative dynamics are observed.

The indicators for the cognitive and moral-volitional components have increased. Distance learning contributed to an increase in the proportion of students with a high level of the cognitive component of readiness for educational and professional self-development (from $25.7 \%$ to $32.2 \%$ ). Future medical workers estimate higher the level of their own general professional and special knowledge, general humanitarian and legal knowledge, including in relation to the healthcare sector. However, no statistical differences were found between the proportions of persons with different levels of cognitive readiness for educational and professional self-development as a result of statistical data processing using the $\varphi *$ criterion (Fisher's angular transformation) $\left(\varphi *_{\text {emp }}<\varphi *_{0.05}\right)$.

Having gained experience in distance learning. students show a higher level of moral and volitional readiness for educational and professional self-development, which is expressed in an increase in criticality and self-criticism, independence, dedication, ability to work, volitional efforts in bringing what has been started to completion, a positive attitude to the learning process, etc. The share of students with a high level of moral and volitional readiness has significantly increased $\left(\varphi^{*}{ }_{\text {emp }}=2.118 ; \varphi^{*}{ }_{\text {emp }}>\varphi^{*}{ }_{0.05}\right)$; at the same time, the share of persons with an average level for this component decreased $\left(\varphi^{*}{ }_{\text {emp }}=2.339 ; \varphi^{*}{ }_{\text {emp }}>\varphi^{*}{ }_{0.01}\right)$.

The indicators for the motivational and communicative components of students' readiness for educational and professional self-development have significantly decreased.

The motivational component manifests itself in the awareness of the personal and social significance of lifelong education in medical activity, the need for professional selfknowledge and self-education, persistent cognitive interests in the field of medicine, a sense of duty and responsibility in the implementation of educational, professional and future professional activities, striving for a high assessment of one's self-educational activities and etc. The number of students with a high level of these indicators has significantly decreased $\left(\varphi^{*}{ }_{\text {emp }}=2.182 ; \varphi^{*}{ }_{\text {emp }}>\varphi^{*}{ }_{0.05}\right)$ and at the same time the number with a low level of 
motivational readiness for educational and professional self-education has increased $\left(\varphi^{*}\right.$ emp $\left.=1.803 ; \varphi^{*}{ }_{\text {emp }}>\varphi{ }^{*}{ }_{0.05}\right)$.

The communicative component of readiness for educational and professional selfdevelopment presupposes the ability to cooperate and provide mutual help with fellow students in professional self-education, organize self-educational activities of others, defend their point of view in discussions, build constructive relationships with the teacher, avoid conflicts in the process of joint activities, etc. the proportion of persons with a high level of severity of these indicators has significantly decreased $\left(\varphi^{*}{ }_{\text {emp }}=3.513 ; \varphi^{*}{ }_{\text {emp }}>\varphi^{*}{ }_{0.01}\right)$ and the proportion of students showing a low level of the communicative component increased $\varphi^{*}$ emp $\left.=2.441 ; \varphi^{*}{ }_{\text {emp }}>\varphi^{*}{ }_{0.01}\right)$.

Despite the absence of statistically significant differences $\left(\varphi^{*}\right.$ emp $\left.<\varphi^{*}{ }_{0.05}\right)$, a slight decrease in the ability to self-government in educational and professional activities and the level of formation of the gnostic component of students' readiness for educational and professional self-development should be noted. The students' self-esteem of the independence of their own activity, the ability for introspection and reflection, self-control, self-organization and mobilization for the fulfillment of educational and professional tasks decreased. Students note a decrease in the flexibility and efficiency of thinking; the ability to analyze educational and professional activities and creativity in its implementation, synthesis and generalization, classification and systematization of information; the ability to extrapolate the acquired knowledge and skills to practical professional situations, as well as a decrease in satisfaction from the learning process.

Positive dynamics was revealed only in the organizational component of readiness for educational and professional self-development, which is expressed in improving the ability to plan time and work, rebuild the system of activities in accordance with the requirements of the situation, use various methods of information processing, navigate the classification of sources, including those presented online -libraries, etc. However, this dynamics is statistically insignificant $\left(\varphi^{*}\right.$ emp $\left.^{<}<\varphi^{*}{ }_{0.05}\right)$.

\section{Conclusions}

Thus, despite the significant efforts of teachers aimed at creating conditions for the implementation of distance learning for students of a medical educational organization - the maximum fullness of educational content, the development of a set of reproductive and creative tasks for students, the provision of systematic and meaningful feedback, the use of various technical means in the educational process and sources of communication, the readiness of students for professional self-education in the context of distance learning is declining. In our opinion, professional education of medical specialists is possible only in conditions of direct interaction of the subjects of the educational process, which is necessary for the involvement of students in educational and professional activities, the formation of internal and external positive motivation, an increase in the level of organization and discipline, readiness and ability for self-development in educational -professional activity. At the same time, the use of distance educational technologies in educational activities in the study of individual sections of academic disciplines can be quite appropriate and effective.

According to the Federal Law No. 164-FZ adopted on June 8, 2020 "On Amendments to Articles 71.1 and 108 of the Federal Law "On Education in the Russian Federation", in the event of emergencies or their threat, the implementation of educational programs and the final state certification is carried out with the use of e-learning, distance educational technologies, regardless of the restrictions provided for in federal state educational standards" [13]. The formalization of the possibility of switching to remote education in the event of a threat of an emergency does not require the consent of the student (or the consent of his parents, legal representatives, in the case of a minor student). 
Taking into account the normative regulation of automatic introduction, if necessary, of distance learning in educational organizations, it is advisable to improve the theory and practice of distance learning. The use of the method of distance educational technologies within the framework of traditional education will increase the efficiency of the educational process and minimize disruptions in the organization of training when transferring educational organizations to a remote format for the implementation of educational activities in the event of local (at the level of a particular region) or global (countrywide) emergencies.

\section{References}

1. A.A. Sevastiyanova, Chelyabinsk State University, 19 (2015)

2. N.P. Narbut, I.A. Aleshkovskiy, A.T. Gasparishvili, O.V. Kruhmaleva, RUDN Journal of Studies in Literature and Journalism, 3 (2020)

3. A. Qayyum, O. Zawacki-Richter, Open and Distance Education in Asia, Africa and the Middle East (2019)

4. D. Orr, M. Weller, R. Farrow, Models for online, open, flexible and technology enhanced higher education across the globe - a comparative analysis (2018)

5. D. Orr, M. Weller, R. Farrow, Journal of Interactive Media in Education, 1 (2019)

6. N. Mheidly, M. Y. Fares, J. Fares, Front. Public Health (2020)

7. E. E. Kuvshinova, Modern Pedagogical Education, 4 (2020)

8. M. Kerres. Postdigital Science and Education (2020)

9. S.E. Rukshin, Sankt-Peterburgskie vedomosti, 101 (2020)

10. A.S. Akanova, N.N. Ospanova, G.M. Abildinova, N.A. Ispulov, Open and distance education, 2 (2020)

11. O.M. Goreva, Modern High Technologies, 12 (2015)

12. N.P. Fetiskin, V.V. Kozlov, G.M. Manuilov, Socio-psychological diagnostics of the development of personality and small groups (2005)

13. Federal Law "On Education in the Russian Federation" dated December 29, 2012 No. 273-FZ (as amended on June 08, 2020), http://www.consultant.ru/ 